\title{
Formando professores para a Educação Inclusiva: a experiência de criação do site "IHA Informa" a partir das demandas e práticas docentes
}

Luiz Alexandre da Silva Rosado, PUC-Rio, alexandre.rosado@globo.com Cristiane Correia Taveira, PUC-Rio e SME/Rio, cristianecorreiataveira@ gmail.com

Resumo: A partir do uso de suportes digitais, que permitem a difusão personalizada de informações para um público delimitado, assim como a geração de conhecimento a partir do amplo acesso a documentos em múltiplos formatos, o artigo tem como objetivo analisar e relatar o percurso de criação e os conteúdos geridos através do site IHA Informa. O site surgiu para atender a professores atuantes no campo da Educação Especial, visando a sua formação continuada, a partir da observação da prática docente, uma Didática vivenciada, com saberes práticos que nascem em meio à urgência da inclusão do aluno com deficiência. Estes saberes devem ser valorizados e utilizados na elaboração de políticas, orientações e estratégias de atendimento visando lidar com a diferença a ser incorporada em sala de aula, um dos muitos aspectos da escola multicultural. Com cerca de 122 mil acessos totais em 2 anos de funcionamento, foram produzidos sete documentos de orientações e criadas seis seções, incluindo materiais multimídia para auxílio ao professor (vídeos e apresentações). São analisados, ao final, os resultados da pesquisa on-line para consulta de necessidades e demandas dos professores visitantes do site, que contava com 116 sujeitos respondentes até o fechamento deste artigo.

Palavras-chave: Formação docente continuada; Saberes práticos; Didática vivida; Tecnologias de informação e comunicação.

\section{Training teachers for Inclusive Education: the experience of creating the site "IHA Reports" from the demands and teaching practices}

\begin{abstract}
From the use of digital media, enabling the dissemination of information to a defined audience, as well as the generation of knowledge from broad access to documents in multiple formats, the article aims to analyze and report the route creation and content managed by IHA Informa website. The site was created to meet the teachers working in the field of Special Education, seeking their continued formation, from the observation of teaching practice, an experienced Didactics with practical knowledge that arise amid the urgency of the inclusion of students with disabilities. Such knowledge should be valued and used in the preparation of policies, guidelines and strategies to meet in order to deal with the difference to be incorporated into the classroom, one of many aspects of the multicultural school. With about 122 thousand hits total in two years of operation, seven guidelines documents were produced and six sections was created, including multimedia materials to aid the teacher (videos and presentations). Finally, we analyze the results of online survey which aimed to see the needs and demands of visiting professors, with 116 respondents to the closing of this article.
\end{abstract}

Keywords: Continuing teacher education; Practical Knowledge; Experienced Didactics; Information and Communication Technologies. 


\title{
1. “O que eu faço agora?!”: formando professores na urgência da educação inclusiva.
}

Esse artigo une investigações de dois campos distintos, porém convergentes. $\mathrm{O}$ primeiro é o campo da formação de professores em Educação Especial e o segundo é o de Tecnologias da Informação e Comunicação (TICs), com foco nos suportes de característica digital e as potencialidades que oferecem às práticas docentes. No âmbito da educação inclusiva, percebemos a necessidade de união das TICs ao processo de criação (e divulgação) de textos, imagens, animações, áudios e vídeos, contendo orientações e materiais auxiliares a docentes, construídos junto a eles a partir de suas próprias práticas observadas em campo.

Quanto ao momento vivenciado hoje pelas escolas no município do Rio de Janeiro, podemos dizer que na pauta de desafios e tensões está a diferença a ser incorporada em sala de aula, incluindo as diferenças étnicas, raciais, culturais, de classe social e as deficiências. A questão da inclusão escolar ou da diferença a ser incorporada na escola gera incômodo. Os desafios apresentados pelas diferenças comportamentais, multiplicidade de características sociais, emocionais, físicas, intelectuais e culturais de alunos tornam o ambiente da escolarização imprevisível na visão do professor. Esses aspectos provocam questionamentos e o enfrentamento de uma realidade de sala de aula complexa. Segundo Tardif \& Lessard (2005),

\begin{abstract}
A escola persegue fins não apenas gerais e ambiciosos, mas também heterogêneos e, às vezes, até potencialmente contraditórios: assegurar o bemestar de todos e garantir o respeito às diferenças; favorecer o sucesso da maioria dos alunos, valorizando, ao mesmo tempo, os alunos mais dotados; funcionar segundo um princípio de igualdade e de cooperação entre todos os alunos e estimular, ao mesmo tempo, a competição, etc. Esses fins podem, com certeza, conciliar-se na retórica educativa, mas no contexto concreto das escolas, onde os recursos são limitados e o tempo contado, eles levantam necessariamente o problema da compatibilidade e da hierarquização. Ou, mais uma vez, esse problema é repassado às mãos dos professores que deverão escolher por si mesmos os fins, em função de seus recursos, crenças, valores (p. 77-78).
\end{abstract}

Pensando na construção e no repasse de orientações para solução de problemáticas comuns na prática de professores, nas múltiplas finalidades da escola, em seus valores e crenças em relação às diferenças individuais, sociais e culturais, verificase a relevância da formação docente em Educação Especial. É dilema central da docência a equidade do tratamento que esses profissionais precisam garantir a todos os alunos, dilema este que se coaduna com o tempo restrito para a busca por recursos de informação e de formação para lidar com essa realidade complexa. Nessa procura situam-se as ferramentas e as concepções trazidas pelas TICs no formato digital.

Sabemos que as TICs potencializam e aceleram a "Era da Informação" ou "Era do Conhecimento" - expressões típicas nos discursos da década de 1990 -, já sintetizadas por autores como Castells $(1999,2003)$ quando examinam a cultura emergente da internet e sua influência nos negócios, na formação comunitária e na política. Para certos autores, conforme análise de Aquino (2008), a informação é a matéria prima básica e para outros o foco está no conhecimento como produção do indivíduo a partir das informações adquiridas, vivenciadas e sintetizadas.

Porém é ponto comum o fato de que a expansão da rede mundial de computadores mudou a relação dos educadores e outros profissionais que lidam com 
informação, apresentando tanto possibilidades quanto desafios. Entre os desafios encontra-se a seleção de conteúdos e a produção/organização de informações que sejam auxiliares específicos na resolução dos problemas que os docentes encontram em seu cotidiano. Se falamos atualmente em Web 2.0, bidirecionalidade, interatividade, também temos que nos conscientizar que um enorme fluxo de dados vem sendo produzido em larga escala por diversos atores participantes da rede (Shirky, 2012), caracterizando o momento atual da cibercultura como aquele em que potencialmente todos podem publicar para todos.

Independente da nomeação e da hierarquia de apreensão das fontes, constatamos no dia a dia a existência de um acúmulo crescente de informações tanto no pólo da produção quanto no pólo da recepção (Lemos, 2004), considerando aqui a díade fundamental da Teoria da Informação. Dessa forma percebemos a necessidade de se aproveitar ferramentas hoje disponíveis gratuitamente na internet para implementar um espaço de acesso comum e coletivo aos professores que necessitam de esclarecimentos práticos, teóricos e técnicos a respeito da Educação Especial.

\section{2. “Onde posso encontrar aqueles documentos do IHA?": alguns problemas em campo transformam-se em espaço para busca de soluções práticas.}

A proclamada turma homogênea é um ideal antigo a qual os docentes buscam atingir, mesmo na tentativa de equilibrá-la com práticas e didáticas que atendam à diversidade de alunos. As diferenças, problemas e dificuldades dos alunos na escola costumam decorrer das expectativas, valores e crenças dos professores, e da sociedade ao qual estamos imersos, em relação à aprendizagem da criança, jovem ou adulto da Educação Especial. Tais fatores acarretam consequências nas percepções sobre 0 processo de escolarização desses alunos e em relação à inclusão escolar.

Os professores da rede municipal de ensino do Rio de Janeiro, em seu processo de formação, necessitam de orientação ao mesmo tempo padrozinada (uniformidade na apresentação dos conteúdos) e flexível (possibilidade de renovação dos dados e materiais disponíveis) para lidar com crianças, jovens e adultos acompanhados pela Educação Especial.

A partir da experiência dos profissionais de equipe de acompanhamento do Instituto Municipal Helena Antipoff ${ }^{l}$ (IHA) foi verificado como problemática comunicacional (antes mesmo da educacional) que o fluxo de informação $e$ comunicação do IHA com professores precisava ser padronizado para em seguida ser replicado. Para esclarecer melhor esta problemática enumeramos alguns fatores observados no cotidiano da instituição e que provavelmente se repetem em outros órgãos responsáveis por atender um contingente de centenas de profissionais:

1) Os documentos e textos de orientação enviados por e-mail facilmente se perdem ou não são acessados pelos destinatários, sendo desviados, por exemplo, para o spam do webmail ou acidentalmente deletados;

2) Os documentos via e-mail exigem intermediários quando enviados pelo webmail para os diretores de escolas, passando por diretores que podem esquecer de repassar o material a todos os professores da instituição que dirigem;

3) E-mails dispersos impossibilitam a visualização em conjunto do histórico de produções com orientações aos profissionais. Nesse caso, os novos professores que chegam para compor a equipe do IHA e os professores que chegam para atuar no campo da Educação Especial ou com alunos da Educação Especial não podem acompanhar de maneira eficaz esse histórico; 
4) Palestras e reuniões para formação em Educação Especial não abrangem o quantitativo de professores que necessitam de informação e/ou da disponibilização de materiais para consulta e estudo.

Essas necessidades foram identificadas logo no início da produção e distribuição dos documentos de orientação produzidos no IHA, sendo percebidas através da dinâmica de encontros com coordenadores das equipes de acompanhamento da Educação Especial, de fevereiro a junho de 2010 (vide metodologia).

Ficavam expressas as perguntas: Como facilitar o envio de informações e de agenda de formação da Educação Especial para as escolas municipais do Rio de Janeiro $^{2}$ ? Como dar acesso a essas informações e formação implementadas no município do Rio de Janeiro? De que maneira poderíamos construir modos de informação e de formação complementares às palestras e reuniões descentralizadas que ocorrem nas dez Coordenadorias Regionais de Educação (CREs) do Rio de Janeiro?

A primeira análise dos dados trazidos nos relatos dos profissionais de equipes de acompanhamento do IHA levavam ao uso da internet como facilitador do acesso à informação, a qualquer momento que professores precisassem de documentos, textos e multimídia de orientação, agendas de eventos e de palestras.

A segunda análise dos dados trazidos dos mesmos relatos se referem ao saber prático, a uma didática vivenciada ou vivida que tenha significado para os professores e que seja referenciada em experiências do dia-a-dia da sala de aula. É sobre esta que falaremos a seguir.

\section{3. “Também tenho algo a dizer!": a procura da valorização de novas práticas frente aos tradicionais modelos de reprodução e fragmentação docente.}

Conforme salienta Candau (1997), há tensões e conflitos no universo de pluralidades - globalização, multiculturalismo, questões de gênero e de raça - com que a escola precisa dialogar e isso não se esgota na imersão nos aspectos da cultura escolar. A problemática se complexifica e os processos em jogo (de valores, da ética, dos saberes) se multiplicam.

A complexidade dos dilemas vivenciados entre objetivos e propostas individuais (felicidade de uma pessoa ou de um grupo específico) ao mesmo tempo em que delimitar objetivos de atenção a metas globais e universais (justiça partilhada por todos) remete ao campo da Educação Intercultural. O conceito de interculturalidade se configura no diálogo entre diversas culturas que conformam uma sociedade multicultural. A Educação Intercultural se materializa como projeto de diálogo, de intercâmbio, de inter-relação de diferentes culturas (Andrade, 2009).

Nos estudos de Candau (1983, 1997, 1998) são ressaltadas as dimensões humanas, político-social e técnica, o que perpassa pelo constante repensar sobre a Didática e a Didática vivida. Já o foco de Tardif \& Lessard (2005) corrobora o pensar sobre o saber-fazer, o saber-prático, o saber da experiência e a formação docente que vão ao encontro do pensar sobre uma Didática vivida a partir de uma valorização do saber docente.

Candau (1997) ressalta a fundamental importância da valorização desse saber docente tanto no âmbito da reflexão sobre a Didática quanto da formação continuada.

Os saberes da experiência fundam-se no trabalho cotidiano e no reconhecimento de seu meio. São saberes que brotam da experiência e são por ela validados. Incorporam-se à vivência individual e coletiva sob a forma de habitus e de habilidades, de saber fazer e de saber ser. É através desses saberes que os professores julgam a formação que adquiriram, a pertinência 
ou o realismo dos planos e das reformas que lhes são propostos e concebem os modelos de excelência profissional (...) (Candau, 1997, p.83).

Os saberes docentes precisam ser valorizados e as pluralidades desses mostram algumas contradições em representações antagônicas e resistentes. Podemos afirmar que ainda vivemos sob influência de representações forjadas no período de auge do industrialismo, especialmente nos grandes centros urbanos. Sob certos aspectos, porque este ainda nos atinge com os seus modelos enraizados na cultura como, por exemplo: a regulação através da exatidão do tempo, a aprendizagem sem valor e significação, o trabalho em grande parte repetitivo e estável.

O modelo de vida do trabalho repetitivo advém do sistema de produção fabril, que é um modus operandi de sociedade que implica em relações, teorias e práticas distintas de outras que emergem em uma sociedade na qual cada vez crescem mais os setores de serviços e a necessidade de inovações e da criatividade. Embora o modelo de criatividade, e consequente valorização da individualidade, também esteja associado ao modelo da competição de mercado baseado na performance centrada no indivíduo (Ball, 2002), torna-se um contraponto interessante que pode ser utilizado a favor do processo docente, quando o objetivo se torna o compartilhamento de práticas e não a simples medição e controle "de eficácia" das mesmas.

Existem saídas possíveis. Entre elas, está o rompimento ou a transformação das modalidades de ensino, informação e comunicação através da ampliação e modificação da formação do profissional de Educação Especial com a introdução das TICs. Numa nova constituição sócio-econômica estaria a surgir outra sociedade em que as TICs, em parte, são emblemáticas ao oferecerem campos de produção criativa (cultura digital) antes restritos aos grandes meios de comunicação (cultura de massa), detentores da difusão de informações, ou aos centros públicos para encontros e trocas (praças, ruas, mercados), mudança esta enfatizada por Lemos (2004, p. 11) quando diz que "a cibercultura potencializa aquilo que é próprio de toda dinâmica cultural, a saber, o compartilhamento, a distribuição, a cooperação, a apropriação dos bens simbólicos."

A docência, como profissão de interações humanas, está imersa e situada nessas transformações; no entanto, a escola moderna (no sentido que atribuímos à modernidade iluminista clássica de origem européia), voltamos a afirmar, reproduz um grande número de características do mundo industrial, fabril e militar (Tardif \& Lessard, 2005), visto que foi constituída por tais valores e para tais finalidades.

Por outro lado, os professores sentem a necessidade de buscar uma formação que atenda à heterogeneidade de alunos, que contemple a diversidade humana, principalmente pela sensação vivenciada, na prática, do insucesso que o modelo educacional em curso apresenta, no confronto com novos e antigos dilemas. Face aos dois extremos, o primeiro da criatividade individual absoluta e o segundo do controle, homogeneização e previsibilidade de práticas docentes, afirmamos aqui a possibilidade de alternativas que valorizem o professor como sujeito criativo, com práticas específicas e originais, sem descartar a divulgação dessas práticas através de documentos acessíveis aos demais, colaborando para uma difusão de práticas locais bem sucedidas.

\section{A construção do site IHA Informa: do surgimento para orientar práticas a uma prática a ser analisada.}

Conforme exposto até agora, a proposta de investigação vem a partir da análise de uma experiência que pretendeu romper com o modelo fabril por meio de ênfase no saber experiencial dos professores, através de uma Didática vivida. Dessa forma, a 
produção de conteúdo para formação docente em Educação Especial precisou aliar a análise das necessidades do profissional do IHA e dos professores em atuação em sala de aula com a ênfase no saber experiencial de professores, a partir de seu contexto.

Nessa pesquisa, em que a ênfase reside na emergência de uma solução a partir da necessidade percebida no campo de atuação de um dos autores, a resultante das análises de dados da instituição somada ao uso e experiência prévia em elaboração de sites pelo outro autor, materializou-se na criação de um veículo de comunicação, orientação $e$ atualização de professores, o "IHA Informa", usando-se como suporte uma plataforma de gestão de conteúdos na internet (Wordpress), para que o acesso à informação produzida a partir das múltiplas experiências docentes fosse realmente efetivado.

\title{
5. Delineando a metodologia de trabalho e estudo.
}

\begin{abstract}
A formação continuada deve alicerçar-se numa "reflexão na prática e sobre a prática", através de dinâmicas de investigação-ação e de investigação formação, valorizando os saberes de que os professores são portadores (Nóvoa, 1992 apud Candau, 1997, p. 84)
\end{abstract}

Em investigação sobre a Didática vivida, a preocupação de Candau (1983, 1997, 1998) em termos de metodologia e pesquisa são compatíveis com Tardif \& Lessard (2005). Pode-se acrescentar que o estudo e a pesquisa dos saberes docentes demandam investigar a utilização de saberes oriundos da experiência profissional, da vivência dos docentes; saberes que são fruto, também, da improvisação regulada a partir de esboços flexíveis de ação, e que possibilitam as variações de acordo com as contingências escolares diversas e sempre em transformação (Tardif \& Lessard, 2005).

Esse trabalho de pesquisa teve a responsabilidade de devolução e produção de website na internet com documentos de orientação que comportassem os desafios surgidos no decorrer da análise de dados, subdividida em três etapas:

1) Dados coletados por meio de discussões (registradas) realizadas com as equipes de acompanhamento do IHA (quatro com o mesmo grupo de dez equipes);

2) Dados coletados por meio de participação na elaboração coletiva de textos de orientação calcados em saberes-práticos e da experiência no campo da Educação Especial para website na internet;

3) Dados coletados a partir da exibição on-line dos documentos, buscas efetuadas pelos visitantes, pesquisa com questões quantitativas e qualitativas, registros de visitas ao site e o formulário acessível no link "Dúvidas".

A idealização da plataforma e as seções construídas ao longo da análise de dados se constituíam necessidades apresentadas pelos elementos de equipes de acompanhamento e a participação dos professores do campo em sua atuação/consulta ao site. Esse modo de conceber a formação mostra a preocupação de o professor refletir sobre a própria prática explicitando saberes tácitos. Esse esforço de reflexão foi realizado num primeiro plano com os profissionais das equipes de acompanhamento do IHA.

\section{A experiência de produção do site IHA Informa e alguns de seus resultados.}

O IHA Informa, que pode ser acessado pelo endereço <http://ihainforma.wordpress.com>, foi lançado em abril de 2010, inicialmente com a sua principal seção, na página inicial, contendo documentos de orientações para professores. 
Até o mês de novembro de 2012 foram publicados os documentos com orientações sobre Deficiência Múltipla; sobre a prática pedagógica e o ensino voltado para o aluno surdo; sobre a prática pedagógica nas classes hospitalares e na itinerância domiciliar; sobre a inclusão do aluno com Transtornos Globais do Desenvolvimento; os documentos do Atendimento Educacional Especializado; as atribuições e a formação em serviço de professores das salas de recursos e de itinerância; e para realização de provas para alunos da educação especial.

Visando as normas internacionais para acessibilidade, pouco a pouco os documentos estão sendo disponibilizados também para leitura em Voz Eletrônica sintetizada em arquivos MP3 associados a cada um dos textos, além da disponibilidade em formato PDF para download, impressão e leitura pelos professores que visitam o site.

Com o passar do tempo outras seções começaram a atender demandas surgidas no campo. Vamos detalhar cada um delas a seguir:

1. Multimídia: a seção de materiais multimídia surgiu a partir dos vídeos exibidos em palestras para professores, tanto dentro quanto fora do IHA. Os vídeos, atualmente disponíveis, envolvem palestrantes internacionais que propõe soluções ou fazem relatos de experiência em temas da Educação. Destacam-se nesse caso os vídeos das conferências anuais TED (Technology, Entertainment, Design), que valorizam experiências e pesquisas marcantes de pessoas em suas respectivas áreas de atuação. Esta seção abriga também a produção local, com:

a. Vídeos produzidos pelo IHA com professores da rede municipal do Rio de Janeiro, se destacando aqueles em que são expostas as produções de materiais adaptados pelos professores do Atendimento Educacional Especializado (AEE) em oficinas promovidas dentro da instituição.

b. Vídeos produzidos por instrutores surdos da rede municipal do Rio de Janeiro, em LIBRAS, com temáticas diversas, visando atender aos alunos em Salas de Recursos.

c. Vídeos produzidos pela Multirio com entrevistas junto a elementos de equipe de apoio do IHA voltado aos professores da rede municipal, com esclarecimentos de temáticas dentro da Educação Especial.

2. Apresentações: esta seção surgiu da necessidade de compartilhar para os professores as apresentações (slides) exibidas durante palestras da instituição. Entre os temas tratados destacam-se a Tecnologia Assistiva, Sudez e intérpretes, Deficiência física, Deficiência visual, Transtornos Globais do Desenvolvimento, Legislação e terminologias e a Avaliação do aluno da Educação Especial. Foram acrescidos também os materiais apresentados nos Encontros de Educação Bilíngue, em que foram convidados especialistas de diversas partes do país para formação presencial dos professores da rede municipal do Rio de Janeiro.

3. Legislação: pretendemos reunir nessa seção os documentos que dizem respeito à inclusão da pessoa com deficiência na escola. Inclui o "Relatório Mundial sobre a Deficiências (OMS)", a "Convenção sobre os Direitos da Pessoa com Deficiência" e os "Marcos político-legais da Educação Especial na perspectiva da Educação Inclusiva".

4. Manuais: nas dinâmicas de reuniões foi solicitado um repositório de manuais técnicos; replicamos os principais manuais de interesse dos diretores das escolas e dos demais profissionais envolvidos no processo: "Manual de acessibilidade espacial para escolas" e "Manual de implantação das Salas de Recursos Multifuncionais". Os referidos manuais são produções da Secretaria de Educação Especial do Ministério da Educação (MEC). 
5. Sobre o IHA: Aqui, além de disponibilizarmos canais de contato com os professores, são expostas e compartilhadas as metas futuras e os objetivos alcançados pelo IHA. Outro documento explica as principais áreas de funcionamento da instituição para aquele que não a conhece.

Além dessas seções, outras duas foram criadas. A "Agenda de Eventos IHA" é periodicamente atualizada contendo as atividades da instituição para que os professores possam participar de cursos, oficinas e atividades de formação continuada presencial. Já a "Pesquisa: O que você quer ver no IHA Informa?" nos possibilita apreender as necessidades expressas no campo e o perfil dos frequentadores do site.

O sistema interno do Wordpress, plataforma gratuita na qual o site foi construído, nos permite acompanhamento em tempo real dos acessos feitos pelos nossos visitantes. Vamos expor e comentar algumas estatísticas importantes para compor o perfil desses visitantes:

1. Até o dia 23 de novembro de 2012 houve um total de 122.997 acessos. A página principal recebeu o maior número de acessos (61.189 ou 49,7\%).

2. Os links mais acessados, em volume total, são aqueles relativos aos downloads dos documentos expostos na página inicial do site (PDFs), sendo que os documentos de preenchimento regular (relatórios e planejamentos) estão em primeiro plano, seguidos pelos documentos de orientação produzidos pelas equipes da instituição. Em primeiro lugar absoluto, apesar de estar no ar há menos tempo, está o link da "Agenda de Eventos IHA", com 2.285 acessos, mostrando a relevância da criação da mesma. O link da Pesquisa "O que você quer ver no IHA Informa?" foi acessado 892 vezes e recebeu 116 respostas.

3. A origem dos visitantes varia bastante, sendo atualmente o Facebook a principal porta de entrada independente (695 acessos). Destaca-se a Wikipédia, no verbete que explica o que é o IHA e tem ao final um link para o IHA Informa: foram 495 acessos por este canal de entrada. E-mails do Yahoo! e Hotmail, Orkut (comunidades de professores do município) e Twitter vêm em seguida com acessos distribuídos entre diversas origens do site. Outros pontos de entrada vêm através de blogs que indicaram o IHA Informa em suas postagens. Pelo baixo número total de acessos via links alternativos, percebe-se que a grande maioria chega ao site via buscadores como o Google e Bing (30.627 acessos) que mantém a maioria absoluta dos acessos iniciais.

Quanto à nossa Pesquisa on-line, tivemos algumas demandas e depoimentos que consideramos pertinente sintetizar e comentar. Quanto à pergunta "Quais CONTEÚDOS você MAIS GOSTOU de acessar no IHA Informa?" percebemos em primeiro lugar, confirmado pelo número de acessos, os textos de orientação postados na página inicial. A multimídia também obteve mobilização através da demanda por mais vídeos, processo que vem sendo atendido com a produção de conteúdos a partir de contribuições dos professores e dos profissionais das equipes do IHA. A necessidade de se manter atualizado quanto a novos eventos institucionais foi manifestada pela demanda da agenda, que continua sendo atualizada de acordo com a disponibilização de novos eventos informados pelas equipes da instituição. Importante informar que a aba "Sobre o IHA" não recebeu comentários, mantendo-se como formalidade a quem se interessar em saber mais sobre a instituição.

Quanto à pergunta "Que CONTEÚDOS você SUGERE para adicionarmos no IHA Informa?", a principal demanda se refere aos textos de orientação sobre a Deficiência Intelectual e a Surdez, com o primeiro em fase de elaboração para postagem futura no site e o segundo já produzido e postado, incluindo os materiais dos Encontros de Educação Bilíngue. Há também o pedido por mais vídeos, o que vem sendo atendido, 
e o pedido de sugestões de materiais pedagógicos e de atividades, podendo compor uma futura seção independente do IHA Informa.

Na questão "Quais PERGUNTAS você gostaria que fossem respondidas no IHA Informa?" são recorrentes as dúvidas sobre o quantitativo da turma, o número máximo de alunos com deficiência em turma comum, incluindo legislação específica. Respondidas em parte, através da seção Apresentações, estão as perguntas e comentários sobre avaliação. Importante informar que a análise de perguntas nos permitiu a confecção da seção de dúvidas frequentes, lançada em março de 2011, intitulada "FAQ".

\section{Conclusões? Não, apenas novas perspectivas.}

Com a análise das demandas apresentadas pelas equipes de acompanhamento do IHA, somadas às análises sobre a recepção, os usos e as intervenções de professores no site IHA Informa, há indícios de que o grupo de professores se investe do poder na resolução de dilemas da Educação e que o mesmo julga procedente e necessário, para si, a formação em Educação Especial.

O site IHA Informa é um dos muitos caminhos a serem trilhados na busca de uma formação continuada que atenda a demandas encontradas no campo. Existe a perspectiva de elaboração de novos materiais e seções de acordo com as demandas docentes. Estão a caminho, nesse momento, outros textos com orientações. Espera-se no futuro a consolidação desse meio de comunicação e difusão de informações, sendo seu aspecto principal a aliança com os saberes práticos dos professores na elaboração dos conteúdos e orientações, característica essa fundamental para que a formação docente continuada seja significativa e contemple as práticas do cotidiano escolar.

No contexto concreto das escolas, como salienta Tardif \& Lessard (2005), dos recursos limitados e do tempo restrito, como detectamos da reclamação da falta do aprimoramento profissional e da informação sobre a Educação Especial, a criação do site gerou ganhos de agilidade na circulação da agenda de eventos e cursos do IHA, e na possibilidade de autonomia para que os professores administrassem os usos dos conteúdos existentes no repositório multimídia do site.

A formação docente pensada no decorrer dessa pesquisa foi ao encontro de uma Didática vivida, conforme nos sugere Vera Candau a partir da valorização do saber docente, tanto o saber internamente vivenciado no grupo de professores integrantes do IHA quanto externamente, no grupo de professores das escolas municipais, usuários e/ou colaboradores do site IHA Informa.

Outras linguagens de formação e fluxos de comunicação e informação foram experimentadas na experiência de criação do site, adquirindo a pertinência, o senso prático e a afinidade da vivência de campo com menor contraste com os planos e as reformas propostas em nível macro. Vale ressaltar que o site, com cerca de 122 mil acessos em 2 anos e meio, pode ser considerado bem sucedido e está em contínuo aperfeiçoamento.

\section{Notas}

\footnotetext{
${ }^{1}$ A instituição é responsável por implementar políticas públicas em Educação Especial nas escolas municipais do Rio de Janeiro. Os profissionais do IHA cumprem duas atribuições básicas: A primeira atribuição é acompanhar os alunos da Educação Especial (por meio de visitas as escolas, palestras e reuniões). A segunda atribuição é formular documentos e orientações direcionadas ao trabalho pedagógico com alunos com deficiência física, deficiência intelectual, deficiência visual, deficiência auditiva, surdez, surdocegueira, deficiência múltipla, transtornos globais do desenvolvimento e altas habilidades e superdotação.
} 
0

\footnotetext{
${ }^{2}$ As escolas municipais do Rio de Janeiro compõem a maior rede pública de ensino da América Latina, com 1.064 escolas, 255 creches próprias e outras 170 conveniadas. São mais de 35 mil professores e 680 mil alunos. Cerca de 5.500 alunos da Educação Especial. As escolas são subdivididas em dez Coordenadorias Regionais de Educação (CRE). Informações disponíveis em <http://www.rio.rj.gov.br/web/sme/exibeconteudo?article-id=96310>
}

\section{Referências bibliográficas}

ANDRADE, Marcelo. (2009). Ética, interculturalidade y educación: en busca de los fundamentos éticos-filosóficos para una educación intercultural. In: ARENA-DOLZ, Francisco; SALAZAR, Daniela Gallegos (Ed.). El ciudadano democrático. Reflexiones éticas para uma educación intercultural. Madrid: Plaza y Valdes, 2009. p. 181-198.

AQUINO, Mirian de Albuquerque. O novo status da informação e do conhecimento na cultura digital. Informação e Sociedade, João Pessoa, n. 1, v. 18, p. 79-100, jan./abr. 2008.

BALL, Stephen J. Reformar escolas/reformar professores e os terrores da performatividade. Revista Portuguesa de Educação, Braga, n. 2, v. 15, p. 3-23, 2002.

CANDAU, Vera Maria. A didática e a formação de educadores. Da exaltação à negação: a busca da relevância. In: CANDAU, Vera Maria (Ed.). A didática em questão. Petrópolis, RJ: Vozes, 1983. p. 13-24.

CANDAU, Vera Maria. A revisão da didática. In: CANDAU, Vera Maria (Ed.), Rumo a uma nova didática. Petrópolis, RJ: Vozes, 1998. p. 167-178.

CANDAU, Vera Maria. Da didática fundamental ao fundamental da didática. In: ANDRÉ, Marli Eliza; OLIVEIRA, Maria Rita (Ed.). Alternativas no ensino da didática. São Paulo: Papirus, 1997. p. 71-95.

CASTELLS, Manuel. A galáxia da internet: reflexões sobre a internet, os negócios e a sociedade. Rio de Janeiro: Jorge Zahar Ed, 2003.

CASTELLS, Manuel. A sociedade em rede. São Paulo: Paz e Terra, 1999.

LEMOS, André. Cibercultura, cultura e Identidade. Em direção a uma "cultura Copyleft"?. Contemporânea: Revista de Comunicação e Cultura, Salvador, n. 2, v. 2, p. 9-22, dez. 2004.

SHIRKY, Clay. Lá vem todo mundo: o poder de organizer sem organizações. Rio de Janeiro: Jorge Zahar Ed., 2012.

TARDIF, Maurice, LESSARD, Claude. O trabalho docente: elementos para uma teoria da docência como profissão de interações humanas. Petrópolis, RJ: Vozes, 2005 . 